\title{
Current English Language References Do Not Satisfy Medical Students' Needs: A study on the Vocabulary of the English Language References and Questions in the Comprehensive Examination of Basic Medical Sciences in Iran
}

\author{
Yadollah Pournia ${ }^{1}$
}

${ }^{1}$ English Language Department, Faculty of Medicine, Lorestan University of Medical Sciences, Khorramabad, Iran.

\section{Article Info}

\section{doi}

Article history:

Received 03 Mar 2019

Accepted 08 Oct 2019

Published 21 Dec 2019

Keywords:

Basic Sciences

Comprehensive Examination

Lexical Coverage

Vocabulary Size

Vocabulary Level

*Corresponding author:

Yadollah Pournia, English Language

Department, Faculty of Medicine,

Lorestan University of Medical Sciences,

Khorramabad, Iran.

Email: ypournia@yahoo.com

\section{Abstract}

Background \& Objective: Given the importance of the English language for medical students, this study investigated the lexical characteristics in the English language references and tests of the Comprehensive Examination of Basic Medical Sciences (CEBMS) in Iran.

Materials and Methods: After the texts of the references were collected and their words were classified, the final texts were analyzed for lexical coverage, vocabulary size and vocabulary level. The lexical coverage of five CEBMS English language tests in the references was also surveyed.

Results: Surveying 89,021 tokens (running words) consisting of 9,683 word types and 5,938 word families showed the lexical coverage of $6.27 \%$ for Coxhead's word list and $6.11 \%$ for Hsu's word list in the English language references of the CEBMS. The vocabulary in none of the five CEBMS English language tests had the $98 \%$ lexical coverage in the references. The vocabulary size in the five references included 5,938 word families, which was much lower than the threshold of at least 8,000 word families. Also, the vocabulary level of the five references was at Level 14

Conclusion: Considering the results of this study, it seems that the English language references of the CEBMS do not satisfy medical students' needs including passing the English language test of the CEBMS and comprehending medical texts in English. Therefore, it is recommended that more English language references with higher lexical characteristics should be introduced by the Iranian Ministry of Health or at least by the relevant instructor.

\section{Introduction}

Although medical students do not often have positive attitudes towards the courses of basic medical sciences (1), these courses are of great importance. Research has shown that there is a very important relationship between the concepts of basic medical sciences and clinical methods (2), these concepts are critical in adopting appropriate clinical decisions (3), ignoring them in medicine will result in disastrous effects (4), and the acceptance or rejection of doctors in different tests depends, to a great degree, on the assessment of their basic science knowledge (5).

Given the importance of basic medical sciences (2, $3,4,5$ ), a comprehensive test of basic medical sciences is administered at the end of the first stage of medical education in Iran to assess medical students' knowledge (6). One of the subjects assessed in the Comprehensive Examination of Basic Medical
Sciences (hereafter CEBMS) in Iran is the English language, whose new references for Specialized English for Medicine 1 (SEM 1) and SEM 2 were introduced to medical universities in a circular by the Iranian Ministry of Health in 2013, and the scores of the exams on these references of the CEBMS have been applied from March 2014 (7) (Table 1).

The English language plays an important role for non-native medical students because they are expected to be able to read specialized medical texts written in English as the first and most important educational resources and materials for medical students (8). Also, in recent years, the modern medical education has emphasized evidence-based medicine, and this has highlighted reading research articles (9). In fact, in high levels, the primary goal of teaching English to students of medical sciences is to help them to read and then to write scientific articles (10). 
Table 1: The English language references of the CEBMS

\begin{tabular}{|c|c|c|}
\hline & Title & Course \\
\hline Book 1 & $\begin{array}{c}\text { Fitzgerald P, McCullagh M, Wright R. English for Medicine in Higher Education Studies. UK: Garnet } \\
\text { Publishing; } 2010 .\end{array}$ & SEM $^{*} 1$ \\
\hline Book 2 & $\begin{array}{c}\text { Glendinning EH, Howard R. Professional English in Use: Medicine. Cambridge, UK: Cambridge University } \\
\text { Press; } 2007\end{array}$ & SEM 1 \\
\hline Book 3 & Voughan J. Medical English. Oxford, UK: Oxford University Press; 1989. & SEM 2 \\
\hline Book 4 & $\begin{array}{c}\text { Tahririan MH, Ameri-Golestan A, Tahririan MA. English for the Students of Medicine. Tehran: SAMT } \\
\text { Publication; } 2011 .\end{array}$ & SEM 2 \\
\hline Book 5 & $\begin{array}{l}\text { Cohen BJ. DePetris A. Medical Terminology: An Illustrated Guide. 7th Ed. Philadelphia: Wolters Kluwer; } \\
2015 .\end{array}$ & $\begin{array}{l}\text { SEM } 1 \text { and } \\
\text { SEM } 2\end{array}$ \\
\hline
\end{tabular}

Learning a language is mainly dependent on learning its vocabulary $(11,12)$ because the first thing needed to understand texts in that language is the knowledge about its vocabulary (11, 13). However, teachers of specialized English courses often do not know what vocabulary their students have to learn (14, 15). In fact, the vocabulary that learners of specialized English courses really need has to be provided (16).

Numerous studies have been conducted on the English language vocabulary, and various word lists have been introduced. One of these word lists was introduced by Coxhead in 2000 as the Academic Word List (AWL). The word list consisted of 570 word families and covered nearly $10 \%$ of the words in academic texts (17). Research papers relevant to word lists have mostly referred to the AWL (7), and this list is probably the most impressive word list of the English language (15).

Some studies have been so far conducted on the words in medical texts by Chen and Ge (18), Wang et al. (19), and Hsu (8). By surveying 155 medical textbooks with around 15 million tokens (running words), Hsu introduced her list as the Medical Academic Word List (MAWL) consisting of 595 word families with more than $10 \%$ coverage in the medical textbooks (8). It seems that Hsu (8) has performed, so far, the most comprehensive research on English vocabulary in medical texts.

Given the importance of basic medical sciences (2, $3,4,5)$, the importance of English for medical students $(8,9,10)$, and the importance of vocabulary in learning a language $(11,12,13,16)$ including English, this study investigated the vocabulary in the English language references of the CEBMS in Iran (7) (Table 1) and analyzed the vocabulary with three criteria of lexical coverage, vocabulary size and vocabulary level. As noted above, learners of specialized English courses have to be provided with the words they need (16). Therefore, this study surveyed whether the English language references of the CEBMS (7) (Table 1) would provide medical students with the required vocabulary or not. The results can provide an overview of the efficacy of the new references - either separately or as a whole - and can present first-hand and useful information for the relevant decision-makers in the Iranian Ministry of Health to make necessary decisions on preserving, enhancing, replacing or changing the order of teaching the references.

One of the issues studied in lexical coverage was the lexical coverage of the English language tests of the CEBMS in the English language references of the CEBMS. The results of this issue can provide useful information for medical students and the designers of the tests. In fact, the results can determine whether the vocabulary used in the tests are in or beyond the scope of the vocabulary in the references.

So far, no research has been conducted on the new English language references of the CEBMS (7) (Table 1) and their efficacy, and also on the lexical coverage of the English language tests of the CEBMS in the references. Therefore, conducting this study is necessary and the results can be useful both for educational authorities of the Iranian Ministry of Health and medical students.

\section{Materials and Methods}

This descriptive study was conducted on the new English language references of the CEBMS in Iran (7) (Table 1) in 2017. It should be noted that in addition to the references in Table 1, the book English in Medicine has also been introduced as a reference. According to the circular by the Iranian Ministry of Health (7) (Table 1), this book had been prepared from the texts of Book 3 of the table (Medical English) by adding additional exercises for each text by the instructors of the English Language Department of Shiraz University of Medical Sciences. Therefore, since the texts of both books are the same, the results for Medical English can be generalizable for English in Medicine. All the words in the main and 
complementary texts of the five references in Table 1 were analyzed. For Book 5 (Medical Terminology), only the case studies were analyzed in accordance with the circular (7) (Table 1). Only the exercises were removed from the texts of the references. The reason was that the exercises of language passages reflect the vocabulary used in the original texts, and if the exercises were not removed, they would increase the frequency of some words falsely. The census sampling method was used in this study.

First, the main and complementary texts of the five books (Table 1) were converted into digital text formats through scanning or typing, and appropriate corrections were made in the file of each book based on the requirements of the software. Then, the typographical errors were corrected in each file using Microsoft Word. The texts of each book were collected in one file saved with the name of the book. The files of the five books were analyzed using the RANGE, which is a free software (20). This software has 29 word lists, and its first 25 lists include the 25,000 most frequently used word families of English known as the lists of the BNC/COCA, which have been prepared based on two corpora (collections of texts) of British and American English, namely the British National Corpus and the Corpus of Contemporary American English (21). After the files were run through the software, the frequency of all the tokens (running words) or word families in the files were calculated. A number of 892 word types consisting of 1,348 tokens ( $1.51 \%$ of all the tokens) were not in any of the 29 lists and needed to be classified. In the next step, these tokens were classified in five separate files including new word families, proper names, compound words, abbreviations, and letter-number combinations. After the tokens were classified and the files runnable by the software were created for the unrecognized tokens, all the corrected files for the five books consisting of 89,021 tokens (running words) were analyzed using the software through investigating three lexical characteristics, which consist of lexical coverage, vocabulary size and vocabulary level.

To study lexical coverage, the lexical coverage of Coxhead's Academic Word List (AWL) (17), Hsu's Medical Academic Word List (MAWL) (8), and the English language tests of the CEBMS in the English language references of the CEBMS was determined. To do this, first the 570 word families of Coxhead's AWL (17) including 3,107 word types, and 588 word families of Hsu's MAWL (8) including 2,464 word types were classified based on the requirements of the software. Seven word families in Hsu's MAWL (8) were removed due do their overlapping with other word families, and the number of the word families reduced from 595 to 588. Afterwards, the final corrected files for the five books were analyzed using the software through the classified word families of these two word lists to determine their coverage in the five English language references. The results were compared with the approximately $10 \%$ coverage reported for the two word lists $(8,17)$.

To study the lexical coverage of the tests, five English language tests of the CEBMS from March 2014 to March 2016 were prepared and converted into digital text formats through scanning and typing in the same way as explained for the five books. Then, the words in each test were classified and a word list runnable by the software was prepared for each test. Next, the coverage of each of the English language tests in the English language references of the CEBMS was determined, and the coverage was compared with the $98 \%$ lexical coverage, as the ideal coverage that is needed to comprehend texts with no help from other resources (22).

To study vocabulary size, the final corrected files of the five books were analyzed using the software RANGE (20) through the 34 word lists, namely the 29 word lists in the software as well as the five word lists prepared in the present study, to determine the frequency of all the tokens and word families in the files. The total of the word families in the English language references of the CEBMS was compared with the criterion of 8,000-9,000 word families required to comprehend English texts with no need to any help from external resources such as a dictionary (23).

To study vocabulary level, the final corrected files of the five books consisting of 89,021 tokens (running words) were analyzed using the twenty-five 1,000 word-family lists of the software to determine the coverage of each 1,000 word-family list. Then, the number of 1,000 word-family levels was counted to reach $95 \%$ coverage of the vocabulary in the five books, which is the least coverage that is needed to comprehend texts with no help from other external resources (22). The last level at which the coverage reached or exceeded $95 \%$ was considered as the vocabulary level for each book.

In the present study, a "word family" refers to a basic word along with all its inflected forms and derivations according to Level 6 of the scale provided by Bauer and Nation (24). For example, the basic word of agree and all its inflected forms and derivations including agreeable, agreeably, agreed, agreeing, agreement, agreements, and agrees form one "word family" with 8 "word types". If, for example, all these 8 word types appear 50 times in a text, there will be 
one "word family" for the basic word of agree, with 8 "word types", and 50 "tokens" or "running words".

\section{Results}

This descriptive study was conducted on the English language references of the CEBMS (7) (Table 1) to investigate lexical coverage, vocabulary size and vocabulary level. The results of lexical coverage of the references showed that 491 of the 570 word families of Coxhead's AWL (17) with a $6.27 \%$ coverage, and 530 of the 588 word families of Hsu's MAWL (8) with a $6.11 \%$ coverage appeared in the references (Table 2 ).

Table 2: Coverage of Coxhead's AWL and Hsu's MAWL in the English language references of the CEBMS

\begin{tabular}{llll}
\hline Word lists & Number of tokens (percentage) & $\begin{array}{l}\text { Number of word } \\
\text { types (percentage) }\end{array}$ & Number of word families \\
\hline Coxhead's AWL & $5.581(6.27)$ & $1.185(12.24)$ & 491 \\
Hsu's MAWL & $5.436(6.11)$ & $1.024(10.58)$ & 530 \\
\hline
\end{tabular}

The analysis of lexical coverage of the five English language tests from March 2014 to March 2016 in the English language references showed that the test of March 2016 had the highest $(91.63 \%)$, and the test of March 2014 the lowest $(79.84 \%)$ coverage in the references. The five tests combined had a coverage of $83.34 \%$ in the five references. In addition, Book 2 had the highest $(63.34 \%)$, and Book 1 the lowest $(40.68 \%)$ lexical coverage of the words in the tests (Table 3 ).

Table 3: Coverage of the English language tests in the English language references of the CEBMS

\begin{tabular}{|c|c|c|c|c|c|c|}
\hline $\begin{array}{l}\text { Test } \\
\text { (Number of words) }\end{array}$ & Book 1 & Book 2 & Book 3 & Book 4 & Book 5 & Total of the books \\
\hline March 2014 & $* 53.35 \%$ & $64.03 \%$ & $69.16 \%$ & $59.28 \%$ & $54.54 \%$ & $79.84 \%$ \\
\hline (253) & ** 135 & 162 & 175 & 150 & 138 & 202 \\
\hline September 2014 & $51.29 \%$ & $71.98 \%$ & $70.68 \%$ & $61.20 \%$ & $62.50 \%$ & $87.06 \%$ \\
\hline$(232)$ & 119 & 167 & 164 & 142 & 145 & 202 \\
\hline March 2015 & $54.58 \%$ & $74.80 \%$ & $72.51 \%$ & $62.21 \%$ & $64.50 \%$ & $87.40 \%$ \\
\hline$(262)$ & 143 & 196 & 190 & 163 & 169 & 229 \\
\hline September 2015 & $49.06 \%$ & $68.91 \%$ & $73.40 \%$ & $61.04 \%$ & $61.04 \%$ & $86.89 \%$ \\
\hline (267) & 131 & 184 & 196 & 163 & 163 & 232 \\
\hline March 2016 & $45.64 \%$ & $73.51 \%$ & $66.20 \%$ & $60.62 \%$ & $70.38 \%$ & $91.63 \%$ \\
\hline ( 287$)$ & 131 & 211 & 190 & 174 & 202 & 263 \\
\hline Total of the tests & $40.68 \%$ & $63.34 \%$ & $63.15 \%$ & $51.42 \%$ & $54.08 \%$ & $83.34 \%$ \\
\hline$(1,015)$ & 413 & 643 & 641 & 522 & 549 & 846 \\
\hline
\end{tabular}

${ }^{*}$ Percentage of common words; ${ }^{* *}$ Number of common words

The analysis of vocabulary size of the references using the 34 word lists showed that the five references consisted of 89,021 tokens (running words) including 9,683 word types and 5,938 word families. Moreover,
Book 3 had the highest (27,789 tokens, 3,391 word families), and Book 1 the lowest (8,099 tokens, 1,394 word families) vocabulary size (Table 4$)$.

Table 4: Vocabulary size of the English language references of the CEBMS

\begin{tabular}{llll}
\hline Book & $\begin{array}{l}\text { Number of } \\
\text { tokens (percentage) }\end{array}$ & $\begin{array}{l}\text { Number of word } \\
\text { types (percentage) }\end{array}$ & Number of word families \\
\hline Book 1 & 8.099 & 1.988 & 1.394 \\
Book 2 & 21.515 & 3.920 & 2.645 \\
Book 3 & 27.789 & 5.032 & 3.391 \\
Book 4 & 14.135 & 2.777 & 1.886 \\
Book 5 & 17.483 & 3.533 & 2.683 \\
Total of the books & 89.021 & 9.683 & 5.938 \\
\hline
\end{tabular}

The analysis of vocabulary level using the twentyfive 1,000 word-family lists of the software showed that Book 1 at Level 5 (at the 5th 1,000 word families),
Book 2 at Level 10, Book 3 at Level 11, and Book 4 at Level 8 fulfilled the least coverage of $95 \%$. However, Book 5 did not fulfil the least coverage of $95 \%$ even at 
Level 25, and the words of this book in the twenty-five 1,000 word lists covered $92.43 \%$ of all the words in the book. Therefore, Book 1 had the lowest vocabulary level (Level 5) showing the lowest vocabulary dispersion over the word lists, and Book 5 had the highest level (more than Level 25) showing the highest vocabulary dispersion. The five books combined fulfilled the least coverage of $95 \%$ at Level 14 (Table 5).

Table 5: Vocabulary level of the English language references of the CEBMS

\begin{tabular}{|c|c|c|c|c|c|c|}
\hline Word lists* & Book 1 & Book 2 & Book 3 & Book 4 & Book 5 & Total of the books \\
\hline 1 - 1st 1,000 WFs** & 69.63 & 70.17 & 66.98 & 64.31 & 63.74 & 66.93 \\
\hline 2 - 2nd 1,000 WFs & 14.04 & 11.59 & 11.42 & 12.10 & 9.54 & 11.44 \\
\hline 3-3rd 1,000 WFs & 9.19 & 6.06 & 7.68 & 11.02 & 5.90 & 7.61 \\
\hline $4-4$ th 1,000 WFs & 1.65 & 2.56 & 2.76 & 3.52 & 3.05 & 2.79 \\
\hline 5 - 5th 1,000 WFs & 0.53 & 1.52 & 1.72 & 1.92 & 2.21 & 1.69 \\
\hline 6 - 6 th 1,000 WFs & 0.78 & 1.00 & 1.20 & 0.98 & 1.33 & 1.10 \\
\hline $7-7$ th 1,000 WFs & 0.21 & 0.873 & 0.85 & 0.86 & 1.08 & 0.83 \\
\hline 8 - 8th 1,000 WFs & 0.16 & 0.58 & 0.81 & 0.36 & 0.89 & 0.64 \\
\hline 9 - 9th 1,000 WFs & 0.36 & 0.33 & 0.62 & 0.44 & 0.69 & 051 \\
\hline $10-10$ th 1,000 WFs & 0.30 & 0.41 & 0.57 & 0.40 & 0.37 & 0.44 \\
\hline 11 - 11th 1,000 WFs & 0.19 & 0.33 & 0.39 & 0.20 & 0.55 & 0.36 \\
\hline 12 - 12th 1,000 WFs & 0.10 & 0.29 & 0.42 & 0.25 & 0.45 & 0.34 \\
\hline 13 - 13th 1,000 WFs & 0.10 & 0.29 & 0.18 & 0.26 & 0.37 & 0.25 \\
\hline $14-14$ th 1,000 WFs & 0.00 & 0.21 & 0.25 & 0.14 & 0.41 & 0.23 \\
\hline $15-15$ th 1,000 WFs & 0.02 & 0.11 & 0.19 & 0.25 & 0.22 & 0.17 \\
\hline $16-16$ th 1,000 WFs & 0.04 & 0.15 & 0.26 & 0.20 & 0.33 & 0.21 \\
\hline $17-17$ th 1,000 WFs & 0.04 & 0.11 & 0.15 & 0.10 & 0.23 & 0.14 \\
\hline 18 - 18th 1,000 WFs & 0.04 & 0.09 & 0.16 & 0.11 & 0.32 & 0.16 \\
\hline 19 - 19th 1,000 WFs & 0.04 & 0.01 & 0.10 & 0.03 & 0.11 & 0.07 \\
\hline 20 - 20th 1,000 WFs & 0.01 & 0.10 & 0.13 & 0.12 & 0.13 & 0.11 \\
\hline 21 - 21st 1,000 WFs & 0.00 & 0.08 & 0.07 & 0.02 & 0.21 & 0.09 \\
\hline 22 - 22nd 1,000 WFs & 0.04 & 0.05 & 0.11 & 0.03 & 0.16 & 0.08 \\
\hline 23 - 23rd 1,000 WFs & 0.02 & 0.01 & 0.02 & 0.00 & 0.05 & 0.02 \\
\hline $24-24$ th 1,000 WFs & 0.00 & 0.01 & 0.03 & 0.02 & 0.04 & 0.02 \\
\hline $25-25$ th 1,000 WFs & 0.01 & 0.02 & 0.04 & 0.00 & $0.05^{* * *}$ & 0.03 \\
\hline 26 - New word families & 0.20 & 0.55 & 0.96 & 0.81 & 2.02 & 0.98 \\
\hline 27 - New proper names & 0.33 & 0.08 & 0.22 & 0.16 & 0.29 & 0.20 \\
\hline 28 - New compound words & 0.00 & 0.03 & 0.01 & 0.01 & 0.01 & 0.01 \\
\hline 29 - New abbreviations & 0.16 & 0.33 & 0.06 & 0.16 & 0.53 & 0.24 \\
\hline $\begin{array}{l}30 \text { - Letters-number } \\
\text { combinations }\end{array}$ & 0.05 & 0.04 & 0.03 & 0.08 & 0.09 & 0.05 \\
\hline 31 - Proper names & 0.90 & 0.75 & 0.93 & 0.47 & 0.68 & 0.76 \\
\hline 32 - Marginal words & 0.30 & 0.45 & 0.37 & 0.13 & 3.01 & 0.86 \\
\hline 33 - Compound words & 0.31 & 0.39 & 0.21 & 0.18 & 029 & 0.27 \\
\hline 34 - Abbreviations & 0.27 & 0.43 & 0.11 & 0.36 & 0.64 & 0.35 \\
\hline Out of the lists & 0.00 & 0.00 & 0.00 & 0.00 & 0.00 & 0.00 \\
\hline Level & 5 & 10 & 11 & 8 & $>25$ & 14 \\
\hline
\end{tabular}

* The 26th to 30th word lists were prepared in this study, and the others belonged to the software; **Word families; *** The total equals $92.43 \%$.

\section{Discussion}

This study was conducted on the English language references of the CEBMS (7) (Table 1). The final corrected texts of the five references were analyzed for lexical coverage, vocabulary size and vocabulary level using the RANGE software (20).

The results showed that 491 of the 570 word families of Coxhead's AWL (17), as the most impressive word list of the English language (15), appeared in the references with a $6.27 \%$ coverage (Table 2$)$. This coverage $(6.27 \%)$ is not considered as appropriate compared to the $10.0 \%$ coverage reported for the list in academic texts (17), its $10.07 \%$ coverage in medical research articles (18), $11.75 \%$ coverage in research papers in high impact factor English journals in the field of nursing (25), $11.17 \%$ in applied linguistics research papers (26), 9.60\% coverage in chemistry research articles (27), and even $14.0 \%$ coverage in social science research articles (28). Moreover, a considerable number of the words of this list (79 word families) did not appear in the five references even once. This result is indicative of the relatively low number of the total words in the references, meaning that the five references do not have enough texts to introduce all or most of the frequent academic words (17). Also, this result reveals 
the low vocabulary level of the five references so that they contain more general words than academic words.

The results also showed that 530 of the 588 word families of Hsu's MAWL (8) appeared in the references with a $6.11 \%$ coverage (Table 2). This coverage $(6.11 \%)$ is not appropriate compared to the $10.72 \%$ coverage reported for the list in medical academic texts (8). Moreover, a considerable number of the words of this list (58 word families) did not appear in the five references even once, showing the relatively low number of the total words and the low vocabulary level of the references.

The test of March 2016 had the highest (91.63\%) and the test of March 2014 the lowest (79.84\%) lexical coverage in the five references. The five tests combined had a coverage of $83.34 \%$ in the references (Table 3). This means that the $98 \%$ coverage, as the ideal coverage for optimal comprehension (22), was not fulfilled for the five tests separately or as a whole, regardless of the year of the tests. In other words, medical students in Iran have to expect to encounter new words (16\% of all the words) in the English language tests of the CEBMS even if they master all the words in the five references introduced by the Iranian Ministry of Health (7). It means that mastering all the words in the references does not guarantee the complete success of Iranian medical students in the English language tests of the CEBMS.

Regarding the vocabulary size of the five references, the results showed that the references consisted of 89,021 tokens (running words) including 9,683 word types and 5,938 word families. Moreover, Book 3 had the highest (27,789 tokens, 3,391 word families) while Book 1 had the lowest $(8,099$ tokens, 1,394 word families) vocabulary size (Table 4). This number of word families is much lower than the criterion of 8,000-9,000 word families required for the optimal comprehension of English texts (23). In other words, learning only the words of the five English language references of the CEBMS does not satisfy the needs of medical students in Iran and does not make them independent in comprehending texts without any help from external resources, and these students need to learn much more vocabulary to comprehend medical texts completely.

The analysis of the vocabulary level of the five references showed that Book 1 fulfilled the least coverage of $95 \%$ at Level 5, Book 2 at Level 10, Book 3 at Level 11 and Book 4 at Level 8. However, Book 5 did not fulfil the least coverage of $95 \%$ even at Level 25 . Therefore, Book 1 had the lowest vocabulary level (Level 5) and Book 5 had the highest level (more than Level 25). The five books combined were at Level 14, meaning that they fulfilled the least coverage of $95 \%$ at
Level 14. The order of vocabulary level in the five books was as follows: Book 1 (Level 5), Book 4 (Level 8), Book 2 (Level 10), Book 3 (Level 11) and Book 5 (more than Level 25) (Table 5). Book 1 and Book 2 have been introduced for SEM 1, Book 3 and Book 4 for SEM 2, and Book 5 for both SEM 1 and SEM 2 (Table 1). Considering the results of vocabulary level, it seems that there is no concordance between the vocabulary level of the five references and the order of teaching them. Therefore, it is recommended that Book 4 with lower vocabulary level should be taught before Book 2 and Book 3. Moreover, teaching Book 5 with the highest vocabulary level after the other four books seems to be more logical.

\section{Conclusion}

Considering the results of the present study on lexical coverage, vocabulary size and vocabulary level of the English language references of the CEBMS (7) (Table 1), it is concluded that these references cannot satisfy Iranian medical students' needs including passing the English language test of the CEBMS and comprehending medical texts in English. Therefore, to satisfy these needs, it is recommended that more English language references with higher lexical characteristics should be introduced by the Iranian Ministry of Health or at least by the relevant instructor. For this purpose, new potential references can be analyzed carefully using a text analysis software before they are introduced. Also, medical students are required to study more diverse English texts beyond the references to be familiar with their extreme field vocabulary.

\section{Acknowledgments}

The sincere help of the Deputy for Research, Lorestan University of Medical Sciences, for the final approval and funding of this study is greatly appreciated.

\section{References}

1. Mazouchian H, Roshangar L, Salek Ranjbarzadeh F, Piri R, Karimi Shoar M, Rasi Marzabadi L. Medical Students' View about the Effects of Practical Courses on Learning the General Theoretical Concepts of Basic Medical Sciences. Res Dev Med Educ. 2014; 3(1):21-3.

2. Kullgren J, Radhakrishnan R, Unni, E, Hanson E. An Integrated Course in Pain Management and Palliative Care Bridging the Basic Sciences and Pharmacy Practice. Am J Pharm Educ. 2013; 77(6):121.

3. Kolluru S, Roesch DM, de la Fuente AA. A MultiInstructor, Team-Based, Active-Learning Exercise to 
Integrate Basic and Clinical Sciences Content. Am J Pharm Educ. 2012; 76(2):33.

4. Jayasinghe $\mathrm{S}$. Catastrophic neglect of the basic sciences in medicine. Lancet. 2012; 379(9833):2239-40.

5. Malau-Aduli BS, Lee AY, Cooling N, Catchpole M, Jose M, Turner R. Retention of knowledge and perceived relevance of basic sciences in an integrated case-based learning (CBL) curriculum. BMC Med Educ. 2013; 13:139.

6. Khazaei M, Iranfar SH, Rezai M, Khajai S. The relation of personal and educational characteristics of medical students cohort entered the medical faculty of Kermanshah University in 2000 and their performance in the 28th comprehensive exam of basic medical sciences. J Med Educ. 2005; 7(2):837.

7. Iranian Ministry of Health. The English Language References of the Comprehensive Examination of Basic Medical Sciences. Circular No. D/500/1909. September 2013. [Persian]

8. Hsu W. Bridging the vocabulary gap for EFL medical undergraduates: The establishment of a medical word list. Lang Teach Res. 2013; 17(4):454-84.

9. Mungra P, Canziani T. Lexicographic studies in medicine: Academic word list for clinical case histories. Ibérica. 2013; 25:39-62.

10. Frazer S. Building Corpora and Compiling Pedagogical Lists for University Medical Students. Hiroshima Studies in Language and Language Studies. 2013; 16:65-88.

11. Hsu W. Measuring the Vocabulary of College General English Textbooks and English-medium Textbooks of Business Core Courses. Electron J Foreign Lang Teach. 2009; 6(2):126-49.

12. Csomay E, Petrović M. "Yes, your honor!": A corpusbased study of technical vocabulary in discipline-related movies and TV shows. System. 2012; 40(2):305-15.

13. Konstantakis N. Creating a Business Word List for Teaching Business English. Estudios de lingüística inglesa aplicada (ELIA). 2007; 7:79-102

14. Mohamad AFN, Jin NY. Corpus-based Studies on Nursing Textbooks. Advances in Language and Literary Studies. 2013; 4(2):21-8.

15. Alizadeh I, Farjami H. Recounting and Fine-Tuning Academic Word List for Four Academic Fields. The Iranian EFL Journal. 2011; 7(3):48-73.

16. Frazer S. Beyond the Academic Word List: providing ESP learners with the words they really need. Proceedings of the BAAL Annual Conference. 2008.41-4.

17. Coxhead A. A New Academic Word List. TESOL Quart. 2000; 34(2):213-38.

18. Chen Q, Ge GC. A corpus-based lexical study on frequency and distribution of Coxhead's AWL word families in medical research articles (RAs). Engl Specif Purp. 2007; 26(4):502-14

19. Wang J, Liang SL, Ge GC. Establishment of a medical academic wordlist. Engl Specif Purp. 2008; 27(4):442-58.

20. Heatley A, Nation ISP, Coxhead, A. Range and Frequency programs. 2002. Available from: http://www.victoria.ac.nz/lals/about/staff/paul-nation. [Last accessed on 2014 Sep 10].

21. Nation ISP, Webb S. Researching and Analyzing Vocabulary. Boston: Heinle Cengage Learning; 2011.

22. Laufer B. What percentage of text lexis is essential for comprehension? In Lauren C, Nordman M, eds. Special language: From Human Thinking to Thinking Machines. Clevedon: Multilingual Matters; 1989: 316-23.

23. Nation ISP. How large a vocabulary is needed for reading and listening? Can Mod Lang Rev. 2006; 63(1):59-82.

24. Bauer L, Nation ISP. Word families. Int J Lexicogr. 1993; 6(4):253-79

25. Pournia Y. A Study on the Most Frequent Academic Words in High Impact Factor English Nursing Journals: A Corpus-based Study. Iran J Nurs Midwifery Res. 2019; 24(1):11-7.

26. Vongpumivitch V, Huang JY, Chang YC. Frequency analysis of the words in the Academic Word List (AWL) and non-AWL content words in applied linguistics research papers. Engl Specif Purp. 2009; 28(1):33-41.

27. Valipouri L, Nassaji H. A corpus-based study of academic vocabulary in chemistry research articles. $J$ Engl Acad Purp. 2013; 12(4):248-63.

28. Chanasattru S, Tangkiengsirisin S. The Word List Distribution in Social Science Research Articles. Arab World English Journal. 2017; 8(4):412-29. 